\title{
Formação em Psicologia Escolar: um Estudo de Levantamento em Universidades Públicas do Nordeste
}

\section{Qualification in Educational Psychology: A Survey Study in Public Universities from Northeastern Brazil}

\author{
Aline Rodrigues Gomes (orcid.org/0000-0003-4686-304X) ${ }^{1}$ \\ Fabiola de Sousa Braz-Aquino (orcid.org/0000-0002-8854-8577)2
}

\begin{abstract}
Resumo
Este artigo apresenta um panorama da formação em Psicologia Escolar Educacional no Brasil depois da implementação das Novas Diretrizes Curriculares Nacionais para os cursos de Psicologia. Partiu-se do estudo de Projetos Políticos Pedagógicos, seus respectivos planos de curso e ementas das disciplinas relacionadas à Psicologia Escolar, de sete Universidades Federais do Nordeste. Os resultados foram organizados em três eixos: Ênfase de formação; Disciplinas referentes à Psicologia Escolar; Referenciais utilizados nas disciplinas, os quais foram discutidos à luz de pesquisas no âmbito da Psicologia Escolar. Verificou-se que as Universidades reestruturaram seus Projetos Políticos Pedagógicos observando e respeitando as exigências propostas pelas citadas Diretrizes. Os resultados suscitaram questionamentos acerca da formação em Psicologia Escolar que vem sendo ofertada nos cursos de graduação em Psicologia, especificamente no que se refere ao desenvolvimento e consolidação de uma formação que garanta uma atuação crítica e condizente com as atuais demandas do contexto educacional brasileiro.
\end{abstract}

Palavras-chave: Psicologia escolar. Formação e atuação profissional. Diretrizes curriculares nacionais para os cursos de Psicologia.

\begin{abstract}
An overview of the qualification in Educational School Psychology in Brazil is presented after the New National Curricular Guidelines implementation for the Psychology courses. We started from the study of Political Educational Projects, their respective course plans and syllabi of the disciplines related to School Psychology, from seven Federal Universities of Northeastern Brazil. The results were organized in three axes: Emphasis of qualification; Disciplines related to School Psychology; References Used in the disciplines and discussed in the light of research in the field of School Psychology. It was verified that the universities restructured their Pedagogical Political Projects from the requirements proposed by the mentioned guidelines. The results raised questions about the qualification in the School Psychology area which has been offered in Psychology undergraduate courses, specifically what concerns
\end{abstract}

\footnotetext{
${ }^{1}$ Universidade Federal da Paraíba, João Pessoa, Brasil. E-mail: alinegomesr@ gmail.com.

${ }^{2}$ Universidade Federal da Paraíba, João Pessoa, Brasil. E-mail: fabiolabrazaquino@gmail.com.
} 
about the development and consolidation of a qualification that guarantees a critical and consistent performance with the current Brazilian educational context demands.

Keywords: School psychology. Professional qualification and action. National curricular guidelines for psychology courses. 


\section{Introdução}

O objetivo desse estudo é conhecer e analisar a formação em Psicologia disponibilizada em Universidade Públicas Federais da região Nordeste depois da efetivação das novas Diretrizes Curriculares Nacionais para os cursos de graduação em Psicologia. Em especial, buscou-se levantar como passou a se configurar a área de Psicologia escolar nos cursos de graduação de instituições de ensino superior, visando ampliar e aprofundar as questões pertinentes à formação/atuação profissional do psicólogo no âmbito da Psicologia Escolar e Educacional no país. A Psicologia Escolar Educacional apresenta-se como uma das áreas mais antigas de atuação em Psicologia. Mesmo anterior à regulamentação da profissão por meio da Lei Federal n. 4.119/62, que oficializou a profissão de psicólogos no Brasil, o conhecimento psicológico já servia de fundamento para responder às questões ligadas à aprendizagem e desenvolvimento.

Como apontam Barbosa e MarinhoAraújo (2010, p. 393), a "relação estabelecida entre Psicologia e Educação revela-se bastante satisfatória para ambas, uma vez que possuem pontos de interesse convergentes, como, por exemplo, a relação entre o desenvolvimento e aprendizagem". Portanto, é necessário que a Psicologia e a Educação se articulem buscando realizar uma intervenção conjunta que priorize a promoção do desenvolvimento humano e a construção da cidadania nos contextos educativos do nosso país.

Para que essa atuação se concretize, é necessário atentar para a realidade do cenário educacional brasileiro, e pensar como acontece a preparação dos profissionais para ingressar nesse campo de trabalho, principalmente no que se refere à formação e atuação dos psicólogos escolares. Segundo Guzzo, Mezzalira, Moreira, Tizzei e Neto (2010) uma profissão ou determinada área de conhecimento se consolida à medida que o conhecimento teórico estabelece relação com a prática e as demandas da realidade. Diante disso, entende-se que a relação entre a Psicologia e a Educação não deve se distanciar dessa afirmativa, o que tornam necessários a discussão e o debate acerca do futuro e das possibilidades de atuação da Psicologia Escolar perante a realidade educacional do nosso país.

$$
\text { Pesquisadores como Barbosa \& }
$$

Marinho-Araújo (2010), Borges-Andrada, Bastos, Andery, Guzzo \& Trindade (2015), Guzzo (2002, 2008), Guzzo, Costa \& Sant'ana (2009), Maluf \& Cruces (2008), Marinho-Araújo (2005), Moreira \& Guzzo (2016), Oliveira \& MarinhoAraújo (2009), Santos \& Toassa (2015) e Souza \& Rocha $(2008,2013)$ referem que durante muitos anos a configuração da Psicologia Escolar Educacional no contexto educacional brasileiro esteve relacionada ao desenvolvimento de práticas adaptativas voltadas para o atendimento individual das crianças. Isso levou à efetivação de uma atuação marcadamente clínica e diagnóstica do profissional de Psicologia nas escolas.

Um marco para as discussões no campo da Psicologia Escolar e Educacional é o trabalho de Patto (1997a, p. 467), que inaugura um posicionamento crítico que defendia a superação de condutas de psicólogos nas escolas baseadas em um modelo clínico tradicional voltado para 
“[...] o diagnóstico e o tratamento de supostos distúrbios físicos e psíquicos situados no aluno que não aprende ou não se ajusta às exigências da escola". Os posicionamentos de Patto (1997a, 1997b) foram fundamentais para debates contemporâneos no interior da Psicologia Escolar Educacional no sentido de ressaltar a necessidade de construção de um perfil profissional que, pela reflexão desde a graduação, contemple as dimensões socioeconômica, política e cultural que perpassam e constituem a sociedade e a Educação Pública Brasileira. A partir de então, a Psicologia Escolar Educacional tem buscado uma atuação crítica que privilegie transformações e incentive os processos reflexivos, para que assim possa ressignificar os saberes e fazeres da Educação (Barbosa \& Marinho-Araújo, 2010; Carvalho \& MarinhoAraújo 2010; Guzzo et al., 2009; Maluf \& Cruces, 2008; Moreira \& Guzzo, 2016; Rocha, 2011; Souza \& Rocha, 2008).

$\mathrm{Na}$ esteira dessas discussões, o tema central das críticas passou a ser a formação e atuação profissional do psicólogo escolar, especialmente os embates teóricos e metodológicos que norteiam as ações desse profissional, que ainda se mantêm desarticulados e insuficientes para responder às demandas sociopolíticas da Educação na sociedade brasileira (Asbahr, Martins \& Mazzoline, 2011; Guzzo，2002，2003，2008，2010; Moreira \& Guzzo, 2016; Peretta, Silva, Naves, Nasciutti \& Silva, 2015; Santos \& Toassa, 2015). Em relação às críticas que foram realizadas sobre a atuação do psicólogo escolar diante das questões educacionais, Moreira e Guzzo (2016) destacam que esse movimento não foi suficiente para efetivar e consolidar a prática desse profissional nos espaços de Educação. Desse modo, a discussão sobre a formação e atuação do psicólogo escolar se mantém atual e relevante, especificamente, no que se refere aos estudos e debates sobre a implementação de propostas para reforma curricular dessa área no Brasil (Bardagi, Bizarro, Andrade, Audibert \& Lassance, 2008; Borges-Andrada et al., 2015; Brasileiro \& Souza, 2010; Gomes, 2002; Guzzo, 2003, 2002; Guzzo et al., 2010; Marinho-Araújo, 2007; Peretta et al., 2015; Santos \& Toassa, 2015; Silva et al., 2016).

Com base no exposto, percebe-se a preocupação existente com uma formação condizente com as realidades sociais presentes no contexto educacional brasileiro. Sobre essa questão, as pesquisas e estudos apontam que todas essas discussões dispararam ações voltadas para a mudança curricular nos cursos de graduação em Psicologia (Carvalho \& MarinhoAraújo, 2010; Cruces, 2008; Marinho-Araújo, 2007; Maluf \& Cruces, 2008; Peretta et al., 2015; Santos \& Toassa, 2015; Seixas, 2014). A esse respeito, destaca-se a construção e efetivação das Novas Diretrizes Curriculares Nacionais para os cursos de graduação em Psicologia no Brasil no ano de 2004, que foi fruto desses questionamentos e discussões. Essa resolução foi aprovada em fevereiro de 2004 pelo parecer n. CNE/CES 0062/04, da Câmera de Educação Superior do Conselho Nacional de Educação, e homologada pelo Ministro de Estado da Educação em 12 de abril de 2004. Depois da homologação no dia 7 de maio de 2004, foram instituídas, a partir da Resolução n. 8, as Diretrizes Curriculares Nacionais para os Cursos 
de Graduação em Psicologia oferecidos nas Instituições de Ensino Superior do País (MEC, Parecer n. 0062/04). Ressalta-se que, em 2011, essa resolução foi alterada, passando a vigorar no país a Resolução n. 05/11, que mantém as Diretrizes Curriculares Nacionais para os cursos de graduação em Psicologia, estabelecendo normas para o Projeto Pedagógico Complementar para a Formação de Professores de Psicologia.

Dessa forma, a partir dessa resolução, fica estabelecido que todos os cursos de Psicologia do País devem estar regulamentados por essa lei, como ressalta o art. $2^{\circ}$ : "As Diretrizes Curriculares para os Cursos de Psicologia constituem as orientações sobre princípios, fundamentos, condições de oferecimento e procedimentos para o planejamento, a implementação e a avaliação deste curso." As Diretrizes Curriculares Nacionais (DCNs) definem para os cursos de graduação em Psicologia estruturação curricular que contemple uma formação ampla para o psicólogo, respeitando a multiplicidade de suas concepções teóricas e metodológicas, originadas em diferentes paradigmas e modos distintos de compreender a ciência, assim como a diversidade de suas práticas e contextos de atuação (Parecer CNE/CES n. 0062/04).

A regulamentação teórico-metodológica proposta pelas DCNs visava provocar mudanças significativas no cenário das instituições formadoras do nosso país, já que exige que os currículos passem por transformações significativas visando a uma formação mais generalista para os cursos de Psicologia, que venham ampliar as experiências teórico- metodológicas em busca de formar um perfil profissional competente e comprometido historicamente com as demandas sociopolíticas que necessitam da ação do/a psicólogo/a na sociedade (Bardagi et al., 2008; Borges-Andrada et al., 2015; Brasileiro \& Souza, 2010; Cruces, 2008; Marinho-Araújo, 2007; Seixas, 2014; Souza \& Rocha, 2008; Peretta et al., 2015; Silva et al., 2016).

Segundo Guzzo et al. (2010), essa conquista consiste em um avanço para a área da Psicologia Escolar Educacional, pois antes da efetivação das DCNs em 2004, a Psicologia Escolar era vista como uma área de aplicação da Psicologia, não sendo esta obrigatória pelo currículo de formação. As DCNs modificaram a estruturação curricular dos cursos de formação em Psicologia no Brasil, exigindo que as instituições formadoras criassem ênfases curriculares ou de aprofundamento de estudos. Sendo assim, ficou definido que os cursos de graduação em Psicologia no país devem ofertar no mínimo duas ênfases para a formação do psicólogo.

As ênfases curriculares são definidas a partir do art. 10 das DCNs como "um conjunto de competências e habilidades dentre aquelas que integram o domínio das competências gerais do psicólogo, compatível com demandas sociais atuais e ou potenciais, e com a vocação e condições da instituição" (Parecer CNE/CES n. 0062/04). Diante disso, Marinho-Araújo (2007) alerta para o fato de que essas ênfases sejam suficientemente abrangentes e acompanhadas pelo detalhamento de competências, bem como pelo conjunto de disciplinas que constituirão $o$ suporte do conhecimento necessário exigido 
para o seu desenvolvimento, pelo formando, assim como para a necessidade de incorporar estágio supervisionado para garantir o desenvolvimento das competências específicas previstas. Desse modo, vislumbrava-se a efetivação de uma formação especializada em algum domínio da Psicologia, o que nos distanciaria do equívoco de meras especializações.

Com base no referido documento, destaca-se, para este estudo, a ênfase de formação "Psicologia e Processos Educativos", a qual se configura como responsável pela formação em Psicologia Escolar. Essa ênfase compreende a concentração nas competências para diagnosticar necessidades, planejar condições e realizar procedimentos que envolvam o processo de educação e de ensinoaprendizagem por meio do desenvolvimento de conhecimentos, habilidades, atitudes e valores de indivíduos e grupos em distintos contextos institucionais em que tais necessidades sejam detectadas (Parecer CNE/CES n. 0062/04).

No que concerne à formação do psicólogo escolar, estudiosos como BorgesAndrada et al., 2015; Carvalho \& Marinho, 2010; Maluf \& Cruces, 2008; Marinho-Araújo, 2007; Rocha, 2011; Rocha e Aguiar, 2010; Santos \& Toassa, 2015; Silva et al., 2016; Vieira, Figueredo, Souza \& Fenner, 2013 defendem a necessidade de construir uma formação teórico-prática, fundamentada no tripé ensino, pesquisa e extensão, que oportunize ao psicólogo que deseja atuar nos espaços de Educação refletir e desenvolver uma atuação crítica alinhada com as atuais demandas sociais brasileiras, favorecendo mudanças nos processos educativos. Seguindo essa linha de pensamento, defende-se neste estudo que, durante os cursos de graduação em Psicologia no Brasil, as disciplinas responsáveis pela ênfase nos "processos educativos" sejam capazes de articular conhecimentos teóricos e metodológicos que possibilitem construir uma formação que privilegie o compromisso ético e social do psicólogo escolar, permitindo assim a consolidação de uma atuação mais crítica e condizente com as demandas educacionais brasileiras, que venha a descontruir os velhos paradigmas da exclusão escolar e privilegie ações emancipatórias e propulsoras do desenvolvimento social e de mudanças da realidade.

No entendimento de Marinho-Araújo (2007), para que isso aconteça, é necessário que essas agências formadoras assumam $\mathrm{O}$ compromisso de orientar uma formação em Psicologia Escolar que privilegie as seguintes ações:

[...] transformações sobre as concepções cristalizadas acerca do desenvolvimento humano, da mudança de foco do fracasso escolar para uma cultura de sucesso escolar, da substituição do paradigma da doença para o da saúde psicológica, da construção de estratégias de intervenção que visem á promoção da saúde e do bem estar dos sujeitos (Marinho-Araújo, 2007, p. 20).

Diante do exposto, espera-se que as transformações e mudanças propostas pelas DCNs para os cursos de graduação em Psicologia efetivem uma formação que garanta 
aos psicólogos que intencionam trabalhar no campo escolar e educacional uma atuação profissional comprometida social e politicamente com as demandas das escolas brasileiras. Com base nessa perspectiva, o presente estudo tem por objetivo analisar como vem sendo ofertada a formação na área da Psicologia Escolar Educacional nos cursos de graduação em Psicologia de Instituições Federais de Ensino da Região Nordeste depois da publicação das novas DCNs para os cursos de graduação em Psicologia. Ressalta-se que essa recolha de informações ocorreu no período de 2013 a 2014.

\section{Percurso Metodológico}

Para atender aos objetivos deste estudo, realizou-se uma pesquisa documental fundamentada em uma abordagem qualitativa. Essa abordagem apresenta-se como a melhor forma para investigar, compreender e explicar os processos e relações sociais de determinado grupo, as análises de discursos e documentos (Minayo, 2006). Nesse processo, destacam-se como principal instrumento de coleta de dados os Projetos Políticos Pedagógicos dos cursos de graduação em Psicologia e o plano de curso e ementas das disciplinas referentes à formação da Psicologia Escolar de Instituições de Ensino Superior Federais do Nordeste.

Como amostra, foram contempladas sete universidades federais da região Nordeste, visto que no período de coleta de dados havia duas instituições de ensino superior que estavam passando por reformulações curriculares em seu Projeto Político Pedagógico. $\mathrm{O}$ acesso aos
Projetos Político Pedagógicos foi realizado de acordo com a disponibilidade das referidas instituições acadêmicas, via internet pelos sites das referidas instituições estudadas ou ainda por meio de contato com os coordenadores dos cursos de Psicologia estudados.

Para análise do material coletado, procedeu-se inicialmente realizando uma leitura aprofundada de todos os Projetos Políticos Pedagógicos, identificando quais as principais ênfases de formação de cada universidade. Logo depois, foi feito um levantamento acerca da área da Psicologia Escolar Educacional e da oferta à formação nessa área. Posteriormente a esses procedimentos, o conjunto de informações obtidas permitiu organizar os resultados nas seguintes temáticas: Ênfase de formação; Disciplinas referentes à área da Psicologia Escolar Educacional e suas respectivas ementas e Referenciais teóricos, que foram discutidas à luz da literatura da área da Psicologia Escolar Educacional.

\section{Resultados e discussão}

Este estudo buscou conhecer os Projetos Políticos Pedagógicos dos cursos de Psicologia de sete Instituições de Ensino Superior Federais do Nordeste que foram propostos a partir das novas recomendações das DCNs para os cursos de Psicologia de 2004 a 2011. Especificamente, a análise se concentrou nas disciplinas, ementas e referências bibliográficas específicas da ênfase em Psicologia Escolar Educacional, visando discutir as relações entre esses documentos e as práticas de psicólogos/as no âmbito educacional. 
Em relação à vigência curricular pósDCNs, verificou-se que os sete cursos de Psicologia das universidades pesquisadas reestruturaram seus Projetos Políticos Pedagógicos a partir das exigências propostas por esse documento. Sob esse aspecto, deve-se ressaltar que a elaboração dos Projetos Políticos Pedagógicos das demais universidades que estão trabalhando de acordo com as Novas Diretrizes não assegura uma formação em Psicologia que seja congruente com as questões da área da Psicologia Escolar Educacional. No entanto, essa nova configuração nos cursos pode influenciar e fortalecer uma formação mais congruente com as diretrizes e as demandas educacionais.

No que se refere a essa discussão, recorre-se a Marinho-Araújo (2007), para quem as reformulações legais implementadas nas instituições não são suficientes para a transformação e constituição do novo, dado que é necessária a inserção ativa e interativa de sujeitos conscientes de seus papéis e funções, assim como da diversidade teórica e metodológica da Psicologia e da especificidade do conhecimento psicológico nos contextos de atuação profissional multidisciplinar. Levando em conta os argumentos supracitados, pretendese discutir no decorrer deste artigo as seguintes temáticas: a) Ênfases de formação; b) Disciplinas referentes à área da Psicologia Escolar Educacional; c) Referencial teórico.

\section{Sobre as ênfases de formação}

A Tabela 1 apresenta todas as ênfases de formação em Psicologia ofertadas pelas Universidades Federais da Região Nordeste. Os dados encontrados apoiam o que propõe o art. 11 das Novas Diretrizes Curriculares para os cursos de graduação em Psicologia, ao indicar que o Projeto Político Pedagógico deve ofertar pelo menos duas ênfases curriculares que assegurem possibilidade de escolha do aluno (Parecer CNE/CES n. 0062/04).

Tabela 1. Ênfases curriculares referentes à formação em Psicologia das Universidades Federais da Região Nordeste

\begin{tabular}{clc}
\hline \hline Universidades & \multicolumn{1}{c}{ Ênfases de Formação Ofertadas } & Quantidade \\
Univ. 1 & $\begin{array}{l}\text { Psicologia e Saúde; Psicologia e Processos } \\
\text { Socioculturais }\end{array}$ & 2 \\
Univ. 2 & Processos Psicossociais e a Construção da \\
& Realidade; Processos clínicos e atenção à saúde & 2 \\
Univ. 3 & Psicologia e Atenção à Saúde; Psicologia e \\
& Processos de Gestão de Pessoas \\
Univ. 4 & Processos Clínicos e Atenção à Saúde; \\
\hline
\end{tabular}


Processos Educacionais; Processos

Psicossociais

Univ. 5 Psicologia Clínica; Psicologia e Saúde Mental

Univ. 6 Processos Clínicos e Saúde Coletiva; Processos

Educativos e de Desenvolvimento-

Aprendizagem

Univ. 7 Psicologia do Trabalho, Psicologia

Educacional, Psicologia Clínica, Psicologia

Social, Neurociência e Avaliação Psicológica

Fonte: Elaborada pelas autoras.

Em relação às ênfases curriculares apresentadas, observa-se ainda uma prevalência no âmbito da saúde como principal área ofertada nas universidades pesquisadas, isso porque os cursos de Psicologia dessas universidades tinham em sua matriz curricular as seguintes ênfases: Psicologia e Saúde; Processos Clínicos e Atenção à Saúde; Psicologia e Atenção à Saúde; Processos Clínicos e Atenção à Saúde; Psicologia Clínica; Psicologia e Saúde Mental; Processos Clínicos e Saúde Coletiva; Psicologia Clínica e Psicologia e Saúde Mental. É importante destacar que, de acordo com as Novas Diretrizes Curriculares, as ênfases curriculares devem ser responsáveis pela oferta de disciplinas que darão suporte para o desenvolvimento do conhecimento específico correspondente à área delimitada de formação.

Esses dados corroboram com estudo realizado por Bardagi et al. (2008), em que 33,8\% dos estudantes recém-formados do curso de Psicologia da Universidade Federal do Rio Grande do Sul atuam na área clínica, justificando essa escolha por ter sido a mais evidenciada e popularizada pela sua instituição de formação em detrimento das demais. É importante mencionar que, no caso deste estudo, a formação oferecida pelo curso na época ainda adotava o Currículo Mínimo de 1962. ${ }^{3}$ Entretanto o estudo realizado por Viera et al. (2013), sobre os cursos de graduação em Psicologia em Belo Horizonte, evidenciou resultados que coincidem com o estudo supracitado, mesmo depois da reforma curricular vigente previstas pelas DCNs, pois as ênfases curriculares ofertadas para a formação profissional também se concentram na área clínica e de saúde.

A respeito dessa discussão, BorgesAndrada et al. (2015) trazem um posicionamento crítico, especialmente relacionado aos currículos instituídos no país para a formação em Psicologia, que, mesmo depois das DCNs, ainda

\footnotetext{
${ }^{3} \mathrm{O}$ currículo mínimo para os cursos de Psicologia foi estabelecido pelo Parecer $n^{\circ} 403$ do Conselho Federal de Educação, aprovado em 19 de dezembro de 1962, que permaneceu em vigência durante mais de 40 anos. "Esse documento baseava-se na transmissão de conhecimentos organizados em um conjunto específico de disciplinas e praticamente não levava em conta ou não se referia ao contexto sociocultural no qual o curso era ministrado" (CFP, 2018, p. 21).
} 
se mantêm reproduzindo uma formação profissional fechada e conservadora focada nos aspectos individuais e intersubjetivos do sujeito. Segundo esses autores, essa concepção acaba desconfigurando as regulamentações teóricas metodológicas defendidas por esse documento, para garantir uma formação mais ampla que possibilite uma aproximação com a realidade brasileira e suas diversas demandas sociais.

Em relação à formação voltada para o campo da Psicologia Escolar e Educacional, apenas três universidades apresentaram ênfases de formação voltadas para essa área, as quais são descritas como: Processos Educacionais; Processos Educativos e de DesenvolvimentoAprendizagem e Psicologia Educacional. Sobre esse aspecto, destaca-se que, além de ofertarem disciplinas obrigatórias, essas instituições contemplam em seu currículo disciplinas de aprofundamento e estágio supervisionado, voltado para o desenvolvimento de competências e habilidades direcionadas para uma formação em Psicologia Escolar e Educacional.

No âmbito dessas discussões, menciona-se que, apesar desse conjunto de disciplinas se constituírem em um avanço para a área da psicologia escolar, tais disciplinas não se configuram como fundamentais para garantir uma formação condizente com as demandas educacionais. É preciso questionar como se estruturam tais componente curriculares, verificar como essas disciplinas estão sendo trabalhadas, quais os conteúdos ministrados para a formação do psicólogo escolar e educacional e de que forma as referências bibliográficas, as metodologias dos docentes e suas filiações teóricas estariam contribuindo para uma formação que responda de forma contemporânea às demandas reais dos contextos educacionais e aos estudos realizados nesse âmbito da Psicologia.

Diante dessa problemática, BorgesAndrada et al. (2015) revelam em seu estudo um cenário preocupante quanto à formação e atuação profissional da Psicologia no Brasil em seus diversos segmentos, tanto no nível de graduação quanto no de pós-graduação. No que se refere à Psicologia Escolar, verificou-se um menor número de profissionais atuantes $(10 \%$ dos entrevistados) e a menos efetivamente comprometida com a sua formação. Segundo os autores, tal concepção pode ser explicada como sendo fruto da "manifestação explícita de que a formação não distingue os campos de atuação profissional e prepara para uma matriz clínica de atuação" (Borges-Andrada et al., p. 868).

As demais ênfases de formação encontradas referem-se respectivamente a: Psicologia e Processos Socioculturais (Univ. 1); Processos Psicossociais e a Construção da Realidade (Univ. 2); Psicologia e Processos de Gestão de Pessoas (Univ. 3); Processos Psicossociais (Univ. 4); Psicologia do Trabalho, Psicologia Social, Neurociência e Avaliação Psicológica (Univ. 7). Segundo Viera et al. (2013), as Novas Diretrizes determinam a necessidade de haver um conjunto de disciplinas e estágio supervisionado articulados de acordo com a ênfase escolhida. Diante dessa informação, deve-se pensar em como está sendo a formação de psicólogos para atuar nos contextos educacionais pautada na perspectiva adotada por essas ênfases, visto que estas não se 
referem à área da Psicologia Escolar Educacional especificamente como área de formação.

Perante essa informação, destacam-se as ênfases de formação Psicologia e Processos Socioculturais (Univ. 1) e Processos Psicossociais e a Construção da Realidade (Univ. 2), visto que essas ênfases poderiam abordar uma formação que contemplasse a área da Psicologia Escolar Educacional. Contudo, percebeu-se que apenas a segunda instituição contempla a Psicologia Escolar como área de formação, visto que procura habilitar o aluno para atuar com responsabilidade e competência nos diversos âmbitos da prática do psicólogo (escolas, organizações, comunidades etc.) no diagnóstico, no planejamento de ações e na solução de problemas. Essas informações apresentaram-se de forma vaga, pois não encontramos mais detalhes sobre como ocorre a formação na área da Psicologia Escolar Educacional diante dessa ênfase, na medida em que a instituição não apresenta disciplinas do núcleo de aprofundamento direcionadas à área da Psicologia escolar educacional.

Destaca-se o fato de que entre as sete universidades estudadas apenas uma apresenta em sua matriz curricular a oferta das seis ênfases de formação, as quais englobam as diversas áreas da Psicologia, como Clínica, Organizacional/Trabalho, Educacional, Social, Neurociência e Avalição Psicológica.

\section{Disciplinas referentes à área da Psicologia Escolar Educacional}

No que se refere às disciplinas relacionadas à área da Psicologia Escolar Educacional, todas as universidades estudadas apresentaram em seus Projetos Políticos Pedagógicos disciplinas obrigatórias nessa área. O Quadro 1 apresenta os dados referentes às disciplinas obrigatórias e complementares dessas instituições.

Quadro 1. Disciplinas referentes à área da Psicologia Escolar Educacional das Universidades Federais da Região Nordeste

\begin{tabular}{|c|c|c|}
\hline Universidades & Disciplinas Obrigatórias & Disciplinas Complementares \\
\hline Univ.1 & Duas disciplinas & Não apresenta disciplinas \\
\hline Univ.2 & Duas disciplinas & Não apresenta disciplinas \\
\hline Univ.3 & Uma disciplina & Não apresenta disciplinas \\
\hline Univ.4 & Uma disciplina & $\begin{array}{l}\text { Duas disciplinas - Núcleo de } \\
\text { aprofundamento }\end{array}$ \\
\hline Univ.5 & $\begin{array}{c}\text { Três disciplinas e Estágio } \\
\text { supervisionado }\end{array}$ & Não apresenta disciplinas \\
\hline Univ.6 & Uma disciplina & $\begin{array}{l}\text { Quatro disciplinas - Núcleo de } \\
\text { aprofundamento }\end{array}$ \\
\hline Univ.7 & $\begin{array}{c}\text { Quatro disciplinas e Estágio } \\
\text { supervisionado }\end{array}$ & $\begin{array}{l}\text { Dez disciplinas - Núcleo de } \\
\text { aprofundamento }\end{array}$ \\
\hline
\end{tabular}

Fonte: Elaborado pelas autoras. 
Conforme exposto Quadro 1, apenas três das sete universidades apresentaram, além das disciplinas obrigatórias, disciplinas complementares da área. Essas três universidades são as responsáveis pela oferta das ênfases de formação em Psicologia Escolar e Educacional, as quais englobam respectivamente: Processos Educacionais (Univ. 4); Processos Educativos e de DesenvolvimentoAprendizagem (Univ. 6) e Psicologia Educacional (Univ. 7). No que se refere à quantidade de disciplinas complementares ofertadas pela Univ. 7, o montante se dá de acordo com a procura dos alunos e a disponibilidade de professores do departamento, sendo assim, não há um padrão fixo de disciplinas para todos os períodos.

Concorda-se com Guzzo et al. (2010) que esses resultados demostram um avanço considerável para a área, pois anteriormente à efetivação das Novas Diretrizes Curriculares a Psicologia Escolar era vista como uma aplicação da Psicologia, não sendo exigida pelo currículo de formação. Contudo, cabe destacar que apenas três universidades apresentaram uma disciplina obrigatória em seu currículo e quatro não apresentam disciplinas complementares na área. Em relação a esse aspecto, observa-se que essas quatro últimas universidades não apresentam em seu Projeto Político Pedagógico ênfases de formação voltada para o campo Educacional. Dessa forma, adverte-se que a formação na área da Psicologia Escolar Educacional dessas instituições de ensino pode gerar um perfil profissional diferente daquele produzido em UNIVERSIDADES onde essa ênfase está sendo mais explorada ou ainda vivenciada de forma equiparada com as demais ênfases.

Percebe-se que essa oferta reduzida das disciplinas obrigatórias referente à área da Psicologia escolar educacional, assim como a ausência de disciplinas e estágios que completem a formação do profissional de Psicologia para atuar nos contextos educacionais ainda é algo recorrente nas referidas universidades. Esses dados evidenciam, conforme Guzzo et al. (2009), que esse tipo de deficiência existente na formação em Psicologia Escolar tem prejudicado a consolidação da identidade do psicólogo que atua na Educação.

Alguns estudiosos da área como Cruces, 2008; Guzzo, 2002, 2003; Guzzo et al., 2010; Marinho-Araújo \& Almeida, 2003; Maluf \& Cruces, 2008 e Rocha, 2011, ao discutir essa problemática, apontam haver uma discrepância entre a formação e a prática profissional de Psicologia referente às demandas da Educação, visto que grande parte dos profissionais de Psicologia que ingressam na Educação alega não ter uma formação que beneficie a sua atuação nos contextos educacionais.

Outro aspecto relevante para essa discussão diz respeito à articulação teóricoprática que muitas vezes é negligenciada durante os cursos de formação. A experiência prática revela-se como uma atividade de suma importância para qualquer formação profissional. Desse modo, é necessário dialogar sobre essa questão, especialmente no que se refere à formação em Psicologia Escolar no Brasil (Santos \& Toassa, 2015). 


\section{Referencial teórico disponibilizado pelas ementas das disciplinas referentes à área da Psicologia Escolar Educacional}

Os resultados encontrados pontuam que quatro universidades não apresentaram em seus currículos os referencias teóricos utilizados nas disciplinas referentes à área da Psicologia Escolar Educacional. Portanto, a discussão irá se concentrar nos dados de três universidades, as quais contemplaram essa informação em seus Projetos Políticos Pedagógicos.

No que tange ao referencial teórico utilizado nas disciplinas referentes á área da Psicologia Escolar Educacional, foi observado que a maioria dos utilizados encontra-se entre os anos de 1990 e 2000. Mesmo compreendendo a importância da produção literária durante esse período, para a Psicologia Escolar em nosso país, é necessário discutir se os temas estudados e as problematizações em torno da área no referido período são suficientes para construir uma ciência e uma profissão condizente com as atuais demandas do cenário educacional brasileiro, pois, como afirmam Guzzo et al. (2009), é de suma importância a articulação entre teoria e prática, assim como a contextualização de referenciais teóricos para a realidade brasileira.

Ante essa afirmação, encontra-se, no estudo realizado por Barbosa (2012), uma análise feita sobre esse recorte de tempo na História da Psicologia Escolar no Brasil. Segundo a autora, o período compreendido entre 1990 e 2000 foi denominado de Psicologia Educacional e Escolar, e a reconstrução provocou debates sobre a ressignificação dos trabalhos teóricos e práticos da área, assim como produziu reflexões sobre temas inovadores, tais como a formação, fundamentação teórica e as práticas do psicólogo no contexto educativo.

Sobre a referida fase da Psicologia Escolar e Educacional em nosso país, é necessário concordar com os autores Barbosa e Marinho-Araújo (2010), quando afirmam que essa fase contribui para o avanço da discussão teórica acerca da atuação do psicólogo escolar, evidenciando para os anos posteriores a construção de mudanças e propostas de novas perspectivas para a área. Contudo, deve-se ressaltar que as discussões e debates em relação a essa problemática não ficaram encerradas depois dessa fase, pois estudiosos da Psicologia Escolar vêm propondo mudanças, novos temas e discussões emergentes à referida área (Marinho-Araújo, 2010, 2014, 2016; Martínez, 2010; Neves, 2011).

Conforme o exposto, é importante mencionar que o discurso transformador $\mathrm{e}$ emancipador estabelecido a partir das formulações críticas direcionadas à atuação e formação da Psicologia Escolar não se esgotou, mas, ao contrário, configuram-se elementos imprescindíveis para a construção de novos caminhos para a área (Guzzo, 2008, 2016; Rocha, 2011; Rocha \& Aguiar, 2010; Souza \& Rocha, 2008). Desse modo, destaca-se que discutir essas questões durante os cursos de graduação fornecem elementos de suma importância para reafirmar o compromisso da Psicologia com a Educação e assim ressignificar o papel do psicólogo escolar educacional nesse espaço (Borges-Andrada et al., 2015; Maluf, 2008; 
Santos \& Toassa, 2015).

\section{Considerações finais}

Este estudo possibilitou analisar como vem sendo disponibilizada a formação na área da Psicologia Escolar Educacional nos cursos de graduação em Psicologia das Instituições Federais de Ensino da Região Nordeste depois que as normas das DCNs foram adotadas. Buscando responder aos objetivos do referido estudo, a análise dos dados se concentrou especialmente na ênfase de formação "Psicologia e Processos Educativos" e seus desdobramentos, tais como disciplinas, ementas e referências bibliográficas, vislumbrando discutir as relações entre esses documentos e a formação e práticas de psicólogos/as no âmbito educacional.

Destaca-se neste trabalho que todos os Projetos Políticos Pedagógicos das universidades estudadas estavam de acordo com exigências propostas pelas DCNs para os cursos de graduação em Psicologia. Sobre a formação em Psicologia Escolar Educacional, verificou-se que apenas três das sete universidades pesquisadas têm ênfases de formação direcionadas especificamente para essa área (Processos Educacionais; Processos Educativos e de Desenvolvimento-Aprendizagem e Psicologia Educacional). Destarte, ressalta-se que o currículo de formação ofertado pelas referidas universidades contemplam disciplinas obrigatórias, disciplinas de aprofundamento e estágio curricular supervisionado voltados para o desenvolvimento de competências e habilidades direcionadas para uma formação em
Psicologia Escolar e Educacional.

Torna-se importante mencionar que as discussões em torno deste estudo trazem questionamentos e considerações sobre a formação em Psicologia Escolar Educacional que demanda debate e reflexão por parte de docentes, pesquisadores e acadêmicos, pois, como pontua Guzzo (2008), repensar politicamente o sentido e o papel do psicólogo em contextos educacionais tem se tornado uma tarefa de extrema importância, que necessita da mobilização dos profissionais que estão em atuação e das instituições responsáveis pela formação desses profissionais.

A esse respeito, percebe-se que, apesar das mudanças propostas pelas DCNs para os cursos de graduação em Psicologia, as instituições formadoras ainda se mantêm fortemente reproduzindo uma formação pautada em aspectos meramente individualistas e adaptacionistas da Psicologia e acabam negligenciando aspectos relevantes para a compreensão da realidade social e uma atuação psicossocial dessa profissão (Marinho-Araújo, 2007; Santos \& Toassa, 2015; Peretta et al., 2015; Silva et al., 2016). No que se refere à Psicologia Escolar Educacional, defende-se neste estudo a necessidade de que as instituições formadoras superem essas questões e possibilitem ao futuro profissional de Psicologia uma imersão no universo da realidade educacional brasileira para que assim possam compreender os processos políticos, econômicos e sociais que perpassam a Educação.

Conforme o exposto, depreende-se que a formação em Psicologia Escolar Educacional precisa enfatizar a (re)significação da identidade 
profissional do psicólogo escolar para assim potencializar o florescer de novas transformações no cenário educacional brasileiro. Assim sendo, defende-se que a ênfase "Processos Educativos", em conjunto com outras ênfases de formação, possa compor o grupo de opções obrigatórias de oferta, o que favoreceria a construção de um perfil profissional crítico e consciente que demarque as especificidades do trabalho do psicólogo no campo da Educação (Borges-Andrada et al., 2015; Peretta \& et al., 2015; Santos \& Toassa, 2016, Silva \& et al.,2016).

Diante disso, recomenda-se a realização de futuros estudos em relação a essa temática que considerem a formação e as pesquisas realizadas pelos docentes que lecionam as disciplinas referentes à área da Psicologia Escolar Educacional, assim como as propostas de trabalho que eles vêm discutindo e estudando nesse campo, com vistas a ampliar as discussões e detalhar mais profundamente os aspectos importantes para a efetivação de uma formação em Psicologia Escolar e Educacional.

\section{Referências}

Asbahr, F. S. F., Martins, E., \& Mazzolini, B. P. M. (2011). Psicologia, formação de psicólogos e a escola: desafios contemporâneos. Psicologia em Estudo, 16(1). Doi: $\quad 10.1590 /$ S141373722011000100019 .

Barbosa, R. M., \& Marinho-Araújo, C. M. (2010). Psicologia escolar no Brasil: considerações. Estudos de Psicologia, 27(3), 393-402. Doi: 10.1590/S0103166X2010000300011.

Barbosa, R. D. (2012). Contribuições para a construção da historiografia da Psicologia
Educacional e Escolar no Brasil. Psicologia: Ciência e Profissão, 32(num. esp.), 104-112. Doi: 10.1590/S1414-98932012000500008.

Bardagi, M. P., Bizarro, L., Andrade, A. M. de J., Audibert, A., \& Lassance, M. C. P. (2008). Avaliação da formação e trajetória profissional na perspectiva de egressos de um curso de Psicologia. Psicologia Ciência e Profissão, 28(2), 304-315. Recuperado de http://pepsic.bvsalud.org/pdf/pcp/v28n 2/v28n2a07.pdf.

Brasileiro, T. S. A., \& Souza, M. P. R. (2010). Psicologia, diretrizes curriculares e processos educativos na Amazônia: um estudo da formação de psicólogos. Revista Semestral da Associação Brasileira de Psicologia Escolar e Educacional, 14(1), 105-120. Doi: 10.1590/S1413-85572010000100012.

Borges-Andrade, J. E., Bastos, A. V. B., Andery, M. A. P. A., Guzzo, R. S. L, \& Trindade, Z. A. (2015). Psicologia brasileira: uma análise de seu desenvolvimento. Universitas Psychologica, 14(3), 865-880. Recuperado de http://www.scielo.org.co/pdf/rups/v14n 3/v14n3a06.pdf.

Carvalho, de T. O., \& Marinho-Araújo, C. M. (2010). Psicologia Escolar e orientação profissional: fortalecendo as convergências. Revista Brasileira de Orientação Profissional, 11(2), 219-228. Recuperado de http://pepsic.bvsalud.org/pdf/rbop/v11 n2/v11n2a07.pdf.

Conselho Federal de Psicologia - CFP. (2018). Ano da formação em Psicologia: revisão das Diretrizes Curriculares Nacionais para os Cursos de Graduação em Psicologia. Brasília: CFP.

Cruces, A. V. V. (2008). A pesquisa na formação de psicólogos brasileiros e suas politicas públicas. Boletim Academia Paulista de Psicologia, XXVIII(2-8), 240-255. Recuperado de http://pepsic.bvsalud.org/scielo.php?scri $\mathrm{pt}=$ sci_arttext\&pid $=$ S1415711X2008000200012.

Gomes, V. L. (2002). A formação do psicólogo escolar e os impasses entre a teoria e a prática. In R. S. L. Guzzo (Org.). Psicologia 
Escolar: LDB e Educação hoje (pp. 65-80). Campinas: Alínea.

Guzzo, R. S. L. (2002). Novo paradigma para a formação e atuação do psicólogo escolar no cenário educacional brasileiro. In R. S. L. Guzzo (Org.). Psicologia Escolar: LDB e educação boje (pp. 131-144). Campinas: Alínea.

Guzzo, R. S. L. (2003). Educação para a liberdade, Psicologia da libertação e Psicologia Escolar: uma práxis para a liberdade. In S. F. C. Almeida (Org.). Psicologia Escolar: ética e competências na formação e atuação do profissional (pp. 169178). Campinas: Alínea.

Guzzo, R. S. L. (2008). Psicologia em instituições escolares e educativas: apontamentos para um debate. In $A n o$ da Psicologia na Educação. Textos geradores (pp. 53-61). Brasília, DF: Conselho Federal de Psicologia.

Guzzo, R. S. L., Costa, A. S., \& Sant'ana I. M. (2009). Formando psicólogos escolares: problemas, vulnerabilidades, desafios e horizontes. In C. M. Marinho-Araújo (Org.). Psicologia Escolar: novos cenários e contextos de pesquisa, prática e formação (pp. 35-52). Campinas: Alínea.

Guzzo, R. S. L., Mezzalira, A. S. C., Moreira, A. P. G., Tizzei, R. P., \& Neto, W. M. de F. S. (2010). Psicologia e Educação no Brasil: uma visão da História e possibilidades nessa relação. Psicologia: Teoria e Pesquisa, 26(n. esp.),. Recuperado de https://www.scielo.br/scielo.php?pid $=\mathrm{S} 0$ 102-

\section{$\underline{37722010000500012 \& \text { script }=\text { sci } \text { arttext\& }}$ tlng=pt.}

Lei n. 4.119 de agosto de 1962. (1962). Dispõe sobre os cursos de formação em Psicologia e regulamenta a profissão de Psicólogo. Brasília - DF. Recuperado de http:/ /www.planalto.gov.br/ccivil_03/leis /1950-1969/L4119.htm.

Marinho-Araújo, C. M. (2005). Psicologia e o desenvolvimento de competências. Boletim Academia Paulista de Psicologia, XXV(2-5), 73-85. Recuperado de http://www.redalyc.org/articulo.oa?id=9
4625212

Marinho-Araújo, C. M. (2007). A Psicologia Escolar nas Diretrizes Curriculares. In $\mathrm{H}$. Campos (Org.). Formação em Psicologia Escolar: realidades e perspectivas (pp. 17-48). Campinas: Alínea.

Marinho-Araújo, C. M., \& Almeida, S. F. C. (2010). Psicologia Escolar: construção e consolidação da identidade profissional (3a ed.). Campinas: Alínea.

Marinho-Araújo, C. M. (2014). Intervenção institucional: ampliação crítica e política da atuação em Psicologia Escolar. In R. S. L. Guzzo (Org.). Psicologia Escolar: desafios e bastidores na Educação pública (pp. 153-175). Campinas: Alínea.

Marinho-Araújo, C. M. (2016). Perspectiva histórico-cultural do desenvolvimento humano: fundamentos para atuação em Psicologia Escolar In M. V. Dazzani \& V. L. T. Souza (Orgs.). Psicologia Escolar Crítica: teoria e prática nos contextos educacionais (pp. 37-57). Campinas: Alínea.

Marinho-Araújo, C. M., \& Almeida, S. F. C. (2003). Psicologia Escolar Institucional: desenvolvendo competências para uma atuação relacional. In S. F. C. Almeida (Org.). Psicologia Escolar: ética e competências na formação e atuação do profissional (pp. 5982). Campinas: Alínea.

Maluf, M. R., \& Cruces, A. V. V. (2008). Psicologia Educacional na contemporaneidade. Boletim Academia Paulista de Psicologia, XXVIII(1-8), 87-99. Recuperado de http://pepsic.bvsalud.org/scielo.php?scri pt $=$ sci_arttext\&pid $=$ S1415 711X2008000100011.

Martinez, A. M. (2010). O que pode fazer o psicólogo na escola?. Em Aberto, 23(83), 39-56. Doi: 10. 34109/2176-6673.

Minayo, M. C. S. (2006). O desafio do conhecimento: pesquisa qualitativa em saúde. São Paulo: Editora Hucitec.

Moreira, A. P. G., \& Guzzo, R. S. L. (2016). Situação-limite e potência de ação: atuação preventiva e crítica em Psicologia 
Escolar. Estudos de Psicologia, 21(2), 204215. Doi: 10.5935/1678-4669.20160020.

Neves, M. M. de B. (2011). Queixas escolares: conceituação, discussão e modelo de atuação. In R. S. L. Guzzo \& C. M. Marinho-Araújo (Orgs.). Psicologia Escolar: identificando e superando barreiras (pp. 175214). Campinas: Alínea.

Oliveira, C. B. E., \& Marinho-Araújo, C. M. (2009). Psicologia Escolar: cenários atuais. Estudos e pesquisas em psicologia, 9(3), 648663. Recuperado de http://pepsic.bvsalud.org/scielo.php?scri $\mathrm{pt}=$ sci_arttext\&pid $=$ S180842812009000300007.

Parecer n. 0062/2004, aprovado em 19 de fevereiro de 2004. (2004). Fixa as Diretrizes Curriculares Nacionais para os cursos de graduação em Psicologia. Brasília. Recuperado de http://portal.mec.gov.br/cne/arquivos/p df/ces062.pdf.

Patto, M. H. S. (1997a). In M. H. S. Patto (Org.). Introdução à Psicologia Escolar (3a ed.). São Paulo: T. A. Queiroz.

Patto, M. H. S. (1997b). Para uma crítica da razão psicométrica. Psicol. USP, 8(1), 4762. Doi: 10.1590/S010365641997000100004.

Peretta, A. A. C. S., Silva, S. M. C., Naves, F. F., Nasciutti, F. M. B., \& Silva, L. S. (2015). Novas diretrizes em tempos desafiadores: formação em Psicologia para atuar na Educação. Psicologia Escolar e Educacional, 19(3), 547-556. Doi: 10.1590/21753539/2015/0193893.

Resolução n. 8, de 7 de maio de 2004. (2004). CNE/CES. Conselho Nacional de Educação/Câmara de Educação Superior. Institui as Diretrizes Nacionais para os Cursos de Graduação em Psicologia. Recuperado de http://portal.mec.gov.br/index.php?opti on $=$ com_content\&view $=$ article\&id $=129$ 91.

Resolução n. 5, de 15 de março de 2011. (2011). CNE/CES. Conselho Nacional de Educação/Câmara de Educação Superior.
Institui as Diretrizes Curriculares Nacionais para os cursos de graduação em Psicologia, estabelecendo normas para o Projeto Pedagógico Complementar para a formação de Professores em Psicologia. Recuperado de http://www.portal.mec.gov.br/index.php ?option $=$ com_content\&view $=$ article\&id $=12991$.

Rocha, M. L. (2011). Desafios da Psicologia e Educação entre a macro e a micropolítica. In R. G. Azzi \& M. H. T. A. Gianfaldoni (Org.). Psicologia e Educação (1a ed., Vol. 1, pp. 199-219). São Paulo: Casa do Psicólogo.

Rocha, M. L., \& Aguiar, K. F. (2010). Entreatos: percursos e construções da Psicologia na rede pública de ensino. Estudos e pesquisas em psicologia, 10(1). Recuperado de http://www.revispsi.uerj.br/v10n1/artigo s/pdf/v10n1a06.pdf.

Santos, F. O., \& Toassa, G. (2015). A formação de psicólogos escolares no Brasil: uma revisão bibliográfica. Psicologia Escolar e Educacional, 19(2). Doi: 10.1590/21753539/2015/0192836

Seixas, P. S. (2014). A formação graduada em Psicologia no Brasil: reflexão sobre os principais dilemas em um contexto pós-Diretrizes Curriculares Nacionais. Tese de doutorado, Programa de Pós-Graduação em Psicologia, Universidade Federal do Rio Grande do Norte, Natal.

Silva, S. M. C., Silva, L. S., Naves, F. F., Costa, A. A., Peretta, S., Nasciutti, F. M. B., \& Lima, N. P. (2016). Formação do psicólogo para atuar na Educação: concepções de coordenadores de curso. Psicologia Ciência e Profissão, 36(1), 48-62. Doi: 10.1590/19823703001082014.

Souza, M. P. R., \& Rocha, M. L. (2008). Políticas educacionais: legislação, formação profissional e participação democrática. In Ano da Psicologia na Educação. Textos geradores (pp. 53-61). Brasília, DF: Conselho Federal de Psicologia.

Souza, M. P. R., \& Rocha, M. L. (2013). Politicas Educacionais: legislação, formação profissional e participação democrática. 
In M. G. D. Facci, M. E. M. Meira \& S. C Tuleski (Orgs.). A exclusão dos "incluidos": uma critica da Psicologia da Educaşão à patologização e medicalização dos processos educativos (2a ed.). Maringá: Editora da UEM.

Viera, C. R., Figueredo, F. R. E., Souza, G. L., \& Fenner, C. M. (2013). A Psicologia da Educação nos cursos de graduação em Psicologia de Belo Horizonte/MG. Revista Semestral da Associação Brasileira de Psicologia Escolar e Educacional, SP, 17(2), 239-248. Doi: 10.1590/S141385572013000200006. 